\title{
Factors Associated with Treatment Response to Antidiabetic Agents in Compliant Type 2 Diabetes Mellitus Patients: A Brief Summary of 5-Year Data
}

\author{
Hasniza Zaman Huri ${ }^{1,2^{*}}$ and Lee Tze Xiang ${ }^{2}$ \\ ${ }^{1}$ Clinical Investigation Centre, Faculty of Medicine, $13^{\text {th }}$ Floor Main Tower, University Malaya Medical Centre, 59100 Lembah \\ Pantai Kuala Lumpur, ${ }^{2}$ Department of Pharmacy, Faculty of Medicine, University of Malaya, Kuala Lumpur 50603, Malaysia \\ *For correspondence: Email: hasnizazh@um.edu.my, hasnizazh@ummc.edu.my_Tel: +603 79676657 \\ Fax: +60379674964
}

Received: 6 March 2013

Revised accepted: 11 January 2014

\begin{abstract}
Purpose: To evaluate the response to diabetic medications and factors influencing drug response in compliant type 2 diabetes mellitus (T2DM) patients.

Methods: A cross-sectional, retrospective study was performed on 100 T2DM patients at the University Malaya Medical Centre (UMMC) who were prescribed with at least one antidiabetic medication between January 2007 and December 2011.

Results: Using data from their medical records, it was determined that both fasting plasma glucose (FPG) and glycated hemoglobin (A1c) levels among all subjects were lower than baseline values. However, the reductions were not significant $(p=0.239$ and $p=0.093)$. Factors that were significantly associated with the response to diabetic medications, include hypertension $(p=0.011)$, sulfonylureas $(p$ $=0.041)$, beta-blockers $(p=0.005)$, and baseline A1c levels $(p<0.001)$.

Conclusion: Treatment of T2DM can be further optimized to ensure that diabetes is well-controlled.

Keywords: Treatment response; Antidiabetics; Type 2 Diabetes Mellitus, Hypertension, Beta-blocker.

Tropical Journal of Pharmaceutical Research is indexed by Science Citation Index (SciSearch), Scopus, International Pharmaceutical Abstract, Chemical Abstracts, Embase, Index Copernicus, EBSCO, African Index Medicus, JournalSeek, Journal Citation Reports/Science Edition, Directory of Open Access Journals (DOAJ), African Journal Online, Bioline International, Open-J-Gate and Pharmacy Abstracts
\end{abstract}

\section{INTRODUCTION}

Management of T2DM can be achieved in two ways, namely, lifestyle modification and pharmacotherapy. In Malaysia, pharmacotherapy is usually initiated when lifestyle modification fails to achieve glycemic targets (i.e., A1c $<6.5 \%$ and $\mathrm{FPG}<6 \mathrm{mmol} / \mathrm{L}$ ) within 3 months [1].

Pharmacotherapy of T2DM involves the use of antidiabetic medications to reduce glycated hemoglobin (A1c) and fasting plasma glucose (FPG) levels to the targeted range. The antidiabetic medications available in Malaysia include insulin, oral hypoglycemic agents (OHAs), and GLP-1 analogue (exenatide) [1]. In the latest Malaysian clinical practice guidelines, metformin was recommended as the first-line agent for the treatment of T2DM [1]. Other OHAs, such as sulfonylureas and thiazolidinediones, can also be used as first-line therapy. OHAs can be used in combination with insulin, exenatide, or other OHAs, if glycemic control is not achieved with monotherapy [1].

According to the Malaysian Statistics on Medicine 2007 [2], metformin, glibenclamide, and gliclazide are among the top 10 drugs used in Malaysia. In the same report, the cost burden of antidiabetic medications was also the second highest in 2007, which was > Ringgit Malaysia (RM) 195 million [2]. Therefore, it is important to 
ensure that the optimum antidiabetic regimen is employed to achieve glycemic control without incurring unnecessary costs.

While foreign data are widely available on the comparative effectiveness of medications for T2DM, local data for Malaysia, data concerning the therapeutic effectiveness of antidiabetic medications are very limited. There is also lack of existing information regarding how the various factors influencing drug response are applied in clinical setting.

Given that antidiabetic drugs are the most utilized drug group in Malaysia, the present study aims to evaluate the response of compliant T2DM patients to diabetes medications, as well as the factors influencing the drug response.

\section{METHODS}

\section{Study population and time frame}

Subjects were patients > 18 years of age who have been diagnosed with T2DM, according to the International Statistical Classification of Diseases and Related Health Problems $10^{\text {th }}$ Revision (ICD-10) code for T2DM (E11.0-E11.9). Subjects were also currently or previously prescribed at least one antidiabetic medication during this study, either as a monotherapy or a combination therapy. This study was conducted between January 2007 and December 2011 at the University Malaya Medical Centre Kuala Lumpur, Malaysia.

\section{Exclusion criteria}

Patients diagnosed with Type 1 Diabetes Mellitus (T1DM) or those diagnosed with T2DM, but never received any antidiabetic medications or non-pharmacological management, were excluded from this study. Patients that were found to be non-compliant to antidiabetic medications were also excluded.

\section{Study Design and Procedures}

The present study was a cross-sectional, retrospective study that was initiated after receiving approval from the Medical Ethics Committee of University of Malaya Medical Centre (UMMC). This study was in accordance with the Declaration of Helsinki ${ }^{3}$.

Patients that fulfilled the requirements of the ICD10 code for T2DM (E11.0-E11.9) were identified using the Hospital Information System (HIS). Subsequently, the medical records were traced and retrieved from the Patient Medical Records
(PMR) office using registration numbers. If the patient's record met all the inclusion criteria, data collection was performed. A total of 100 eligible subjects were identified via convenient sampling and their records were retrieved for this study. A minimum sample size of 93 patients was determined to be necessary for statistical purposes using Epi Info, version 6 (Centers for Disease Control and Prevention, Atlanta, GA).

Demographic information and clinical characteristics, including age, gender, ethnicity, height, weight, duration of diabetes, comorbidities, history of taking antidiabetic drugs, other concurrent medications, FPG, A1c, and other laboratory results, of each patient were extracted using the Data Collection Form.

A "treatment response" was defined as an achievement of the glycemic targets (i.e., A1c < $6.5 \%$, FPG < $6 \mathrm{mmol} / \mathrm{L}$ ) [1]. The minimum period required prior to assessing the response to diabetic medications was 3 months after baseline recording, which was defined as the first recording available for FPG and A1c levels [1].

\section{Data analysis}

The baseline and recent levels of FPG and A1C were analyzed qualitatively and quantitatively using Pearson's Chi-squared test and paired samples t-test. The most recent $\mathrm{A} 1 \mathrm{c}$ reading was chosen as an indicator of response to the antidiabetic medications. The mean and standard deviation of recent $A 1 c$ levels were calculated for each patient characteristic and medication. For each of these factors, an independent samples ttest was performed to assess its significance in the response to the antidiabetic medication(s).

All data were pooled and analyzed using IBM SPSS Statistics 20.0 (Armonk, NY, USA). Categorical results were presented in the form of frequency tables and graphs. Numerical results were expressed as mean \pm standard deviation (SD). Comparisons between groups were conducted by using t-test and ANOVA. The results were considered as statistically significant if the $p$ value was less than 0.05 .

\section{RESULTS}

\section{Demographic and social characteristics}

The demographic and social characteristics of the study population are presented in Tables 1 and 2. Two-thirds of the subjects were below the age of 65 and almost all of the subjects were drug and alcohol-free, and most (79 \%) were 
Table 1: Demographic characteristics of the study population

\begin{tabular}{lcc}
\hline Demographic characteristics $\mathbf{( n = 1 0 0 )}$ & $\mathbf{N}$ & $\mathbf{\%}$ \\
\hline Gender & 100 & 100.0 \\
Male & 55 & 55.0 \\
Female & 45 & 45.0 \\
Age & 100 & 100.0 \\
18-64 years old & 63 & 63.0 \\
$\geq 65$ years old & 37 & 37.0 \\
Ethnicity & 100 & 100.0 \\
Malay & 38 & 38.0 \\
Chinese & 19 & 19.0 \\
Indian & 41 & 41.0 \\
Others & 2 & 2.0 \\
\hline
\end{tabular}

Table 2: Social characteristics of the study population

\begin{tabular}{lcc}
\hline Social characteristics & $\mathbf{N}$ & $\%$ \\
\hline Smoking history & 100 & 100.0 \\
Smoker & 10 & 10.0 \\
Non-smoker & 79 & 79.0 \\
Ex-smoker & 11 & 11.0 \\
Alcohol consumption & 100 & 100.0 \\
Yes & 5 & 5.0 \\
No & 95 & 95.0 \\
Drug abuse & 100 & 100.0 \\
Yes & 0 & 0.0 \\
No & 100 & 100.0 \\
Family history of T2DM* & 100 & 100.0 \\
Yes & 8 & 8.0 \\
No & 92 & 92.0 \\
\hline
\end{tabular}

${ }^{*} T 2 D M=$ type 2 diabetes mellitus.

non-smokers. Most (92\%) of the subjects did not have a family history of T2DM.

\section{Clinical characteristics}

There were an increasing number of subjects with a longer duration of T2DM (Table 3). A total of $28.9 \%$ had suffered from T2DM for $>20$ years.

The most frequently encountered comorbidity among the study subjects was hypertension (Figure 1).

Table 3: Duration of type 2 diabetes mellitus among the study population

\begin{tabular}{lcc}
\hline $\begin{array}{l}\text { Duration of T2DM* } \\
\text { (year, } \mathbf{n = 7 6 )}\end{array}$ & $\mathbf{N}$ & $\%$ \\
\hline$<1$ & 0 & 0.0 \\
$1-5$ & 11 & 14.5 \\
$6-10$ & 12 & 15.8 \\
$11-15$ & 15 & 19.7 \\
$16-20$ & 16 & 21.1 \\
$>20$ & 22 & 28.9 \\
Total & 76 & 100.0 \\
\hline \multicolumn{2}{c}{${ }^{*}$ T2DM = type 2 diabetes mellitus. }
\end{tabular}

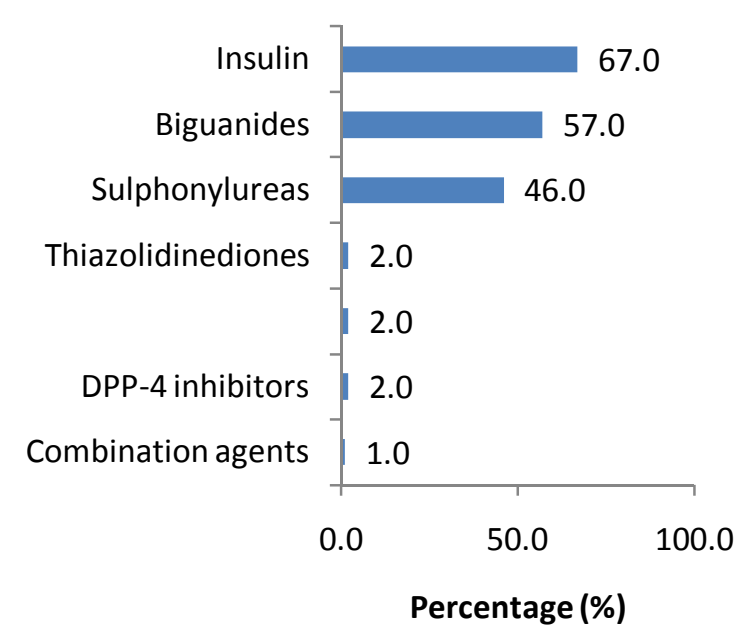

Figure 1: Types of antidiabetic medication used by the study subjects

\section{Antidiabetic medication use}

The majority of subjects $(45.0 \%)$ consumed only one antidiabetic agent, $36.0 \%$ two and $19.0 \%$ more than two. With regard to the types of antidiabetic medications used, the three most common types were insulin, biguanides, and sulfonylureas. Among these drug groups, insulin was the most utilized antidiabetic agent, with $67.0 \%$ of the subjects taking insulin. The rates of biguanide and sulfonylurea use were 57.0 and 
$46.0 \%$, respectively. The other types of antidiabetic agents, such as thiazolidinediones, a-glucosidase inhibitors, DPP-4 inhibitors, and combination agents, were rarely being taken (Figure 2).

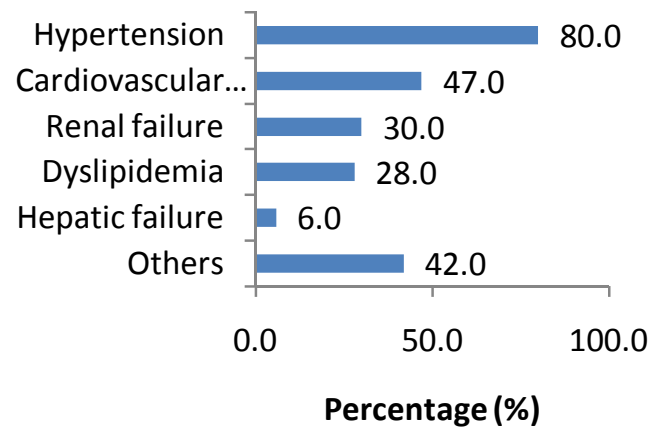

Figure 2: Distribution of comorbid conditions

Table 4 illustrates the number of patients prescribed a certain type of antidiabetic medication. Among the 67 insulin users, a combination of actrapid and insulatard was used by the majority of patients $(88.0 \%)$. Regular metformin was utilized by 56 out of 57 biguanide users $(98.2 \%)$, while 37 out of 46 sulfonylurea users $(80.5 \%)$ were prescribed with gliclazide. Rosiglitazone, acarbose, sitagliptin, and janumet (sitagliptin and metformin) were the only thiazolidinedione, a-glucosidase inhibitor, DPP-4 inhibitor, and combination agents used, respectively, among the study subjects.

\section{Use of Concurrent Medications}

Statins were the most commonly prescribed concurrent medication, with $70.0 \%$ of subjects receiving statins. This was followed by aspirin (46.0\%), ACE inhibitors (45.0\%), and calcium channel blockers (44.0\%). Beta blockers, diuretics, clopidogrel, ticlopidine, nitrates, and angiotensin receptor blockers were also in the top ten drug groups used by the study subjects.
The distribution of the top ten concurrent medications used by the T2DM patients is summarized in Figure 3.

Table 4: Patients prescribed a certain type of antidiabetic medication

\begin{tabular}{|c|c|c|}
\hline Antidiabetic type & $\mathbf{N}$ & $\%$ \\
\hline Insulin & 67 & 100.0 \\
\hline $\begin{array}{l}\text { Actrapid + } \\
\text { Insulatard }\end{array}$ & 59 & 88.0 \\
\hline Mixtard & 4 & 6.0 \\
\hline Lantus & 2 & 3.0 \\
\hline Actrapid only & 1 & 1.5 \\
\hline Insulatard only & 1 & 1.5 \\
\hline Biguanides & 57 & 100.0 \\
\hline $\begin{array}{l}\text { Regular } \\
\text { metformin }\end{array}$ & 56 & 98.2 \\
\hline $\begin{array}{l}\text { Extended- } \\
\text { release } \\
\text { metformin }\end{array}$ & 1 & 1.8 \\
\hline Sulfonylureas & 46 & 100.0 \\
\hline Gliclazide & 37 & 80.5 \\
\hline Glibenclamide & 7 & 15.2 \\
\hline Glipizide & 2 & 4.3 \\
\hline Thiazolidinediones & 2 & 100.0 \\
\hline Rosiglitazone & 2 & 100.0 \\
\hline $\begin{array}{l}\alpha \text {-glucosidase } \\
\text { inhibitors }\end{array}$ & 2 & 100.0 \\
\hline Acarbose & 2 & 100.0 \\
\hline DPP-4 inhibitors & 2 & 100.0 \\
\hline Sitagliptin & 2 & 100.0 \\
\hline $\begin{array}{l}\text { Combination } \\
\text { agents }\end{array}$ & 1 & 100.0 \\
\hline Janumet & 1 & 100.0 \\
\hline
\end{tabular}

* DPP-4 = dipeptidyl peptidase-4

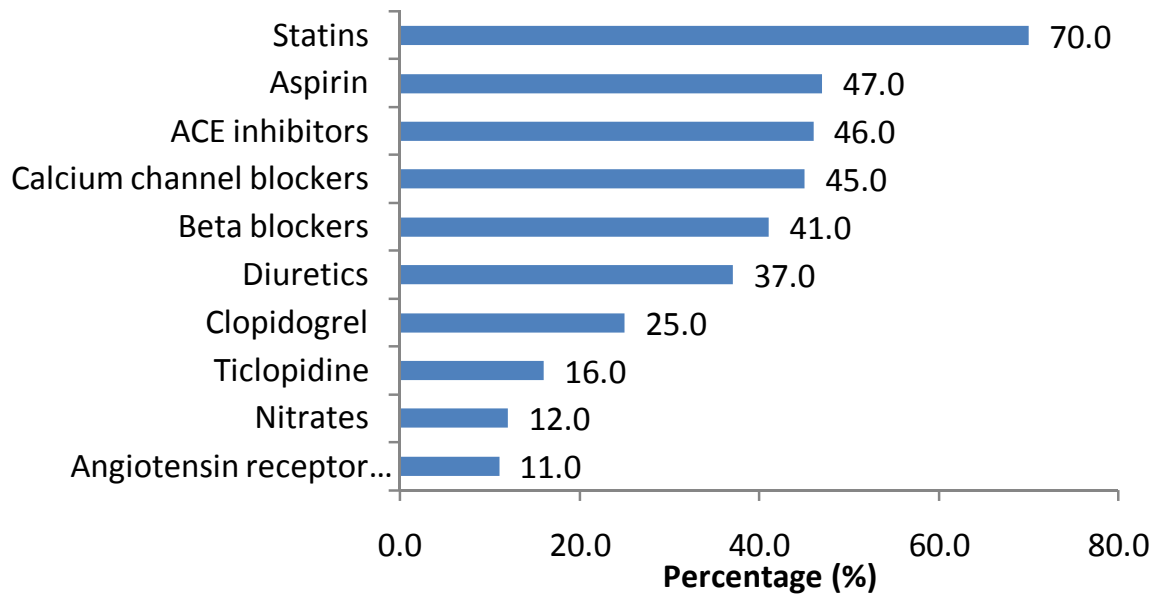

Figure 3: Concurrent use of medication among patients with type 2 diabetes mellitus (Patients may have more than one concurrent medication) 
Among the 70 statin users, simvastatin was the most commonly used statin (82.9\%). Perindopril was the leading ACE inhibitor, with 40 out of 46 subjects $(87.0 \%)$ on ACE inhibitors using it. Amlodipine was used by 39 out of 45 subjects $(86.5 \%)$ on calcium channel blockers, making it the most popular calcium channel blocker. Metoprolol was the most prominent beta-blocker, with 20 out of 41 subjects $(48.8 \%)$ on betablockers using it. A breakdown of the drugs for indications other than T2DM is summarized in Table 5.

Table 5: Distribution of individual concurrent medications among patients with type 2 diabetes mellitus

\begin{tabular}{lcc}
\hline $\begin{array}{l}\text { Concurrent drug type } \\
\text { and name }\end{array}$ & N & $\%$ \\
\hline Statins & 70 & 100.0 \\
Simvastatin & 58 & 82.9 \\
Atorvastatin & 9 & 12.9 \\
Lovastatin & 2 & 2.8 \\
Rosuvastatin & 1 & 1.4 \\
ACE inhibitors & 46 & 100.0 \\
Perindopril & 40 & 87.0 \\
Lisinopril & 3 & 6.5 \\
Enalapril & 2 & 4.3 \\
Captopril & 1 & 2.2 \\
Calcium channel blockers & 45 & 100.0 \\
Amlodipine & 39 & 86.5 \\
Diltiazem & 2 & 4.5 \\
Felodipine & 2 & 4.5 \\
Nifedipine & 2 & 4.5 \\
Beta-blockers & 41 & 100.0 \\
Metoprolol & 20 & 48.8 \\
Atenolol & 14 & 34.1 \\
Bisoprolol & 4 & 9.8 \\
Carvedilol & 2 & 4.9 \\
Propanolol & 1 & 2.4 \\
\hline
\end{tabular}

Abbreviations: ACE, angiotensin-converting enzyme

\section{Clinical Progress of T2DM}

\section{Qualitative Analysis}

There were no significant associations between baseline FPG and recent FPG $(p=0.634)$. There were also no significant associations between baseline $A 1 c$ and recent $A 1 c$ levels $(p=0.408)$. Quantitative Analysis

Initially, the normality of FPG and A1c levels were determined using Shapiro-Wilk Test. The mean \pm S.D. for baseline FPG and recent FPG were $11.63 \pm 5.25 \mathrm{mmol} / \mathrm{L}(p<0.001)$ and 10.44 $\pm 5.71 \mathrm{mmol} / \mathrm{L}(p<0.001)$ respectively. The baseline A1c and recent A1c were 9.30 $12.95(p$ $<0.001)$ and $8.76 \pm 2.52 \%(p<0.001)$ respectively. It was determined that all levels had a $p$-value of $<0.05$, indicating that the values are not normally distributed. However, for the purpose of this study, all of the parameters were assumed to be normally distributed.

We then compared the baseline and recent values using paired samples t-test. There were no significant differences $(p=0.239)$ between baseline (11.61 \pm 5.15) and recent FPG $(10.59 \pm 5.98)$ levels. Additionally, there were no significant differences $(p=0.093)$ between baseline $(9.45 \pm 3.03)$ and recent $A 1 \mathrm{c}$ levels $(8.74 \pm 2.51)$.

\section{Factors associated with response to antidiabetic medications Hypertension}

There is a significant association between hypertension and recent A1c levels $(p=0.011)$. Subjects with hypertension had lower recent A1C levels $(8.45 \pm 2.34) \quad$ compared to subjects without hypertension $(10.61 \pm 2.91)$.

\section{Sulfonylureas}

There was a significant association between the use of sulfonylureas and recent $A 1 c$ levels $(p=$ $0.041)$. Subjects prescribed with sulfonylureas had lower recent A1c levels (8.11 \pm 2.16) compared to subjects who were not prescribed with sulfonylureas $(9.34 \pm 2.71)$.

\section{Beta-blockers}

There was a significant association between the use of beta-blockers and recent A1c levels ( $p=$ 0.005). Subjects prescribed with beta-blockers had higher recent A1c levels (9.69 \pm 2.74$)$ compared to subjects who were not prescribed with beta-blockers $(7.98 \pm 2.05)$.

\section{Baseline A1c levels}

There was a significant association between baseline A1c and recent A1c levels $(p<0.001)$. Subjects with normal baseline A1c levels had lower recent $A 1 c$ levels (6.15 \pm 0.82$)$ compared to subjects with abnormal baseline A1c levels (9.09 \pm 2.46$)$.

Factors not associated with response to antidiabetic medications

All other parameters examined were not significantly different baseline $\mathrm{A} 1 \mathrm{c}$ and recent A1c levels, shown as in Table 6 , indicating that demographic, clinical, comorbidities and drug intakeare not significantly associated with recent A1c levels. 
Table 4: Factors not significantly associated with recent $A 1 c$ levels

\begin{tabular}{|c|c|c|c|}
\hline \multirow{2}{*}{ Parameter } & \multicolumn{2}{|c|}{ Recent A1c (\%) } & \multirow{2}{*}{$\begin{array}{c}P \text { - } \\
\text { value }\end{array}$} \\
\hline & Mean & S.D. & \\
\hline \multicolumn{4}{|l|}{ Gender $(n=70)$} \\
\hline Male $(n=36)$ & 8.76 & 2.68 & \multirow[t]{2}{*}{$0.999^{\mathrm{a}}$} \\
\hline Female $(n=34)$ & 8.76 & 2.39 & \\
\hline \multicolumn{4}{|l|}{ Age $(n=70)$} \\
\hline $18-64$ years old $(n=43)$ & 9.13 & 2.58 & \multirow[t]{2}{*}{$0.126^{a}$} \\
\hline$\geq 65$ years old $(n=27)$ & 8.17 & 2.37 & \\
\hline \multicolumn{4}{|l|}{ Ethnicity $(n=70)$} \\
\hline Malay $(n=28)$ & 8.91 & 2.90 & \multirow{3}{*}{$0.367^{\mathrm{b}}$} \\
\hline Chinese $(n=13)$ & 7.86 & 2.44 & \\
\hline Indian $(\mathrm{n}=29)$ & 9.01 & 2.15 & \\
\hline \multicolumn{4}{|l|}{ Smoking history $(n=70)$} \\
\hline Smoker $(n=8)$ & 8.88 & 1.90 & \multirow{3}{*}{$0.700^{\mathrm{b}}$} \\
\hline Non-smoker $(n=53)$ & 8.63 & 2.47 & \\
\hline Ex-smoker $(n=9)$ & 9.40 & 3.43 & \\
\hline \multicolumn{4}{|l|}{ Alcohol drinking $(n=70)$} \\
\hline Yes $(n=3)$ & 11.23 & 2.02 & \multirow[t]{2}{*}{$0.083^{a}$} \\
\hline No $(n=67)$ & 8.65 & 2.50 & \\
\hline \multicolumn{4}{|c|}{ Family history of T2DM $(n=70)$} \\
\hline Yes $(n=6)$ & 8.23 & 2.57 & \multirow{2}{*}{$0.598^{\mathrm{a}}$} \\
\hline No $(n=64)$ & 8.81 & 2.54 & \\
\hline \multicolumn{4}{|l|}{ Duration of T2DM ( $n=57)$} \\
\hline $1-5(n=7)$ & 9.30 & 2.27 & \multirow{5}{*}{$0.429^{b}$} \\
\hline $6-10(n=10)$ & 7.90 & 1.99 & \\
\hline $11-15(n=12)$ & 8.01 & 3.00 & \\
\hline $16-20(n=12)$ & 9.23 & 2.79 & \\
\hline$>20(n=16)$ & 9.41 & 2.44 & \\
\hline Cardiovascular disease & & & \\
\hline $\begin{array}{l}(n=70) \\
\text { Yes }(n=35)\end{array}$ & 8.79 & 2.35 & $0.922^{a}$ \\
\hline No $(n=35)$ & 8.73 & 2.72 & \\
\hline Renal failure $(n=70)$ & & & \\
\hline Yes $(n=19)$ & 8.41 & 2.53 & $0.492^{\mathrm{a}}$ \\
\hline No $(n=51)$ & 8.89 & 2.54 & \\
\hline Dyslipidemia $(n=70)$ & & & \\
\hline Yes $(n=23)$ & 8.76 & 2.45 & $0.996^{a}$ \\
\hline No $(n=47)$ & 8.76 & 2.59 & \\
\hline $\begin{array}{l}\text { No. of diabetes medications } \\
(n=70)\end{array}$ & & & \\
\hline One $(n=26)$ & 8.65 & 2.83 & $0.832^{b}$ \\
\hline Two $(n=26)$ & 9.00 & 2.47 & \\
\hline More than two $(n=18)$ & 8.57 & 2.22 & \\
\hline Insulin $(n=70)$ & & & \\
\hline Yes $(n=54)$ & 9.06 & 2.62 & $0.063^{\mathrm{a}}$ \\
\hline No $(n=16)$ & 7.73 & 1.92 & \\
\hline Biguanides $(n=70)$ & & & \\
\hline Yes $(n=43)$ & 8.88 & 2.35 & $0.604^{a}$ \\
\hline No $(n=27)$ & 8.56 & 2.81 & \\
\hline Statins $(n=70)$ & & & \\
\hline Yes $(n=55)$ & 8.73 & 2.54 & $0.880^{a}$ \\
\hline No $(n=15)$ & 8.85 & 2.56 & \\
\hline Aspirin $(n=70)$ & & & \\
\hline Yes $(n=34)$ & 8.59 & 2.17 & $0.581^{\mathrm{a}}$ \\
\hline No $(n=36)$ & 8.92 & 2.84 & \\
\hline ACE inhibitors $(n=70)$ & & & \\
\hline Yes $(n=35)$ & 9.15 & 2.49 & $0.198^{\mathrm{a}}$ \\
\hline No $(n=35)$ & 8.37 & 2.53 & \\
\hline Calcium channel blockers & & & \\
\hline$(n=70)$ & & & $0.052^{\mathrm{a}}$ \\
\hline Yes $(n=35)$ & 8.17 & 2.16 & \\
\hline No $(n=35)$ & 9.34 & 2.75 & \\
\hline
\end{tabular}

\section{DISCUSSION}

It was determined that there is a significant reduction in recent $A 1 c$ levels in subjects with hypertension compared to subjects without hypertension. This may be an anomaly in the results, as previous reports showed that patients with hypertension tend to have higher blood glucose levels compared to those without hypertension [4, 5]. Ruggenenti and WhaleyConnell suggested that there is a correlation between elevated blood pressure and insulin resistance $[6,7]$. A possible reason for this anomaly is the relatively small sample size compared to other studies.

It was determined that there is a significant reduction in recent $A 1 c$ levels in subjects prescribed with sulfonylureas compared to subjects not prescribed with sulfonylureas. Krentz \& Bailey (2005) reported that monotherapy with sulfonylureas can reduce FPG and A1c levels by $2-4 \mathrm{mmol} / \mathrm{L}$ and $1-2 \%$, respectively [8].

Previous studies have shown that biguanides are similarly efficacious to sulfonylureas with respect to reducing $\mathrm{A} 1 \mathrm{C}$ levels when compared to placebo [8, 9]. However, in the present study, A1c levels in patients prescribed with biguanides were higher than those not prescribed with biguanides. Potential reasons behind may be small sample size and different patient characteristics.

It was found that there is a significant increase in recent $A 1 c$ levels in subjects prescribed with beta-blockers compared to subjects not prescribed with beta-blockers. In the present study, atenolol (48.8\%) and metoprolol (34.1\%) were the most commonly prescribed betablockers, both of which are of the nonvasodilating type.

Fonseca (2010) reported that non-vasodilating beta-blockers are associated with glucose and lipid abnormalities because they reduce cardiac output without affecting peripheral vascular resistance [10]. Vasodilating beta-blockers, such as carvedilol and nebivolol, are reported to have less impact on insulin sensitivity and glycemic control, as well as reduce the risk of new onset diabetes [11]. Sander \& Giles (2010) also recommended the use of vasodilating betablockers to decrease cardiovascular morbidity and mortality without exposing patients to undesirable side effects on glucose metabolism [12]. 
There is a significant increase in recent $\mathrm{A} 1 \mathrm{C}$ levels in subjects with abnormal baseline A1C levels compared to subjects with normal baseline A1c levels. Subjects whose baseline A1c levels were well-controlled generally have a lower risk of therapeutic failure with diabetes medications. Turner et al. (1999) noted that patients who are more hyperglycemic have a lower probability of achieving glycemic targets [13].

\section{Study limitation}

This study only took into account information that is readily available from medical records. Thus, some other factors that may affect the response of patients to antidiabetic medications, but were not available in the medical records, may not have been considered.

\section{CONCLUSION}

Although the recent $F P G$ and $A 1 c$ levels were lower compared to their baseline values, their reductions failed to achieve significance. Hypertension, sulfonylureas, beta-blockers, and baseline A1c levels were significantly associated with a response to antidiabetic medications. In conclusion, further optimization with respect to the pharmacotherapy of T2DM is warranted to ensure that the diabetic condition of patients is well-controlled.

\section{CONFLICTS OF INTEREST}

The authors have no conflicts of interest to report.

\section{ACKNOWLEDGMENT}

The authors would like to thank the University of Malaya, Malaysia for financial (RG428/12HTM) and technical support.

\section{REFERENCES}

1. Ministry of Health Malaysia. Clinical Practice Guidelines on the Management of Type 2 Diabetes Mellitus $4^{\text {th }}$ ed. 2009. Available from: URL: http://www. acadmed.org. my/index.cfm?\&menuid $=67$

2. Pharmaceutical Services Division and the Clinical Research Centre. Malaysian Statisticson Medicine 2007 2007. Available from: URL: http://www. pharmacy.gov.my/aeimages//File/MSOM2007_2.pd $f$

3. WMA. Declaration of Helsinki. Ethical principles for medical research involving human subjects. 59th WMA General Assembly. 2008. Seoul. Available from: URL: http://www.wma.net/en/30publications/ 10policies/b3/17c.pdf

4. Gress TW, Nieto FJ, Shahar E, Wofford MR, Brancati FL. Hypertension and antihypertensive therapy as risk factors for type 2 diabetes mellitus. $N$ Engl $J$ Med 2000; 342: 905-912.

5. Kumar NL, Deepthi J, Rao YN, Deedi MK. Study of lipid profile, serum magnesium and blood glucose in hypertension. Biol Med 2010; 2: 6-16.

6. Ruggenenti $P$, Cattaneo $D$, Loriga $G$, Ledda $F$, Motterlini $N$, Gherardi G, Orisio S, Remuzzi G. Ameliorating hypertension and insulin resistance in subjects at increased cardiovascular risk: Effects of acetyl-Lcarnitine therapy. Hypertension 2009; 54: 567-574.

7. Whaley-Connell A, Sowers JR. Hypertension and insulin resistance. Hypertension 2009; 54: 462-464.

8. Krentz AJ, Bailey CJ. Oral antidiabetic agents: current role in type 2 diabetes mellitus. Drugs 2005; 65: 385-411.

9. Bennett WL, Maruthur NM, Singh S, Segal JB, Wilson LM, Chatterjee R, Marinopoulos SS, Puhan MA, Ranasinghe $P$, Block L, Nicholson WK, Hutfless S, Bass EB, Bolen S. Comparative effectiveness and safety of medications for type 2 diabetes: An update including new drugs and 2-drug combinations. Ann Intern Med 2011; 154: 602-613.

10. Fonseca VA. Effects of $\beta$-blockers on glucose and lipid metabolism. Curr Med Res Opin 2010; 26: 615629.

11. Deedwania P. Hypertension, dyslipidemia, and insulin resistance in patients with diabetes mellitus or the cardiometabolic syndrome: Benefits of casodilating $\beta$-blockers. J Clin Hypertens 2011; 13: 52-59.

12. Sander GE, Giles TD. Thiazide diuretics and $\beta$-blockers in the treatment of hypertension in diabetes mellitus. J Clin Hypertens 2011; 13: 296-300.

13. Turner RC, Cull CA, Frighi V, Holman RR. Glycemic control with diet, sulfonylurea, metformin, or insulin in patients with type 2 diabetes mellitus: progressive requirement for multiple therapies (UKPDS 49). UK Prospective Diabetes Study (UKPDS) Group. JAMA 1999; 281: 2005-2012. 